\title{
Adding Calcite and Nanocalcite to Improving the Plastic Properties of the Lean Clay
}

\author{
Rasool Yazarloo ${ }^{1}$, Fereshte Aslani Katooli ${ }^{1}$, Mahdi Golestani ${ }^{1}$, Mahdi Asadi ${ }^{2}$, Sadegh Ebrahimi ${ }^{1}$ \\ ${ }^{1}$ Shams Institute of Higher Education, Department of Civil Engineering \\ Shadi st., Gonbad Kavoos, Iran \\ r.yazarloo@modares.ac.ir; f.aslani@iaug.ac.ir; m_golestani@iaug.ac.ir \\ ${ }^{2}$ Islamic Azad University of Gonabad, Department of Civil Engineering \\ Abshar st., Gonabad, Iran \\ m.asadi@iaug.ac.ir; s.ebrahimi@iaug.ac.ir
}

\begin{abstract}
The stabilization of the problematic soils with the calcite and nanocalcite is one of the economically efficient methods in civil projects. The current study evaluated the effect of calcite and nanocalcite on the plastic properties of the clayey soil obtained from the north-east of Iran. The origin of this clay was the loess soil classified as CL in the unified classification system. The purpose of this study was to investigate the effect of adding typical calcite powder and nanocalcite powder (based on the type and amount) on the performance of the improved soil in these two materials. The ball mill machine was used for preparing the nanocalcite. According to the results of X-Ray and SEM tests, the chemical composition of the nanoparticles after crushing was similar to the initial chemical compound of the main powder. The Atterberg limit tests were conducted by adding different weight percentages of calcite including 3 , 4,6 and $7 \mathrm{wt} \%$ and nanoparticles of calcite including $0.5,1,1.5$ and $2 \mathrm{wt} \%$. The results indicated that adding calcite led to the decrement of the plastic index and increment of plastic limit in the studied clayey soil. Furthermore, the mixing percent of the nanocalcite was considerably lower than the typical calcite, but the effect of nanocalcite on improving the clayey soil properties was similar to the calcite particles. Accordingly, the activity of calcite particles in the soil was highly increased due to the crushing of calcite particles in nanoscale and the increase in the specific surface.
\end{abstract}

Keywords: Soil improvement, Calcite, Nanocalcite, Atterberg limit

\section{Introduction}

The soil in the engineering science is a non-integrated mixture of minerals and rotten organic materials and the empty space between them is filled with water and air (gas) [1]. As a construction material, the soil has been used in important projects of civil engineering and the foundation of many structures is dependent on it. Therefore, the civil engineers should study the soil properties such as origin, grain size distribution, permeability, settlement, shear strength, bearing capacity and so on. Soil mechanics is a branch of engineering science that study the physical properties and the soil mass behavior under the different loading conditions. Foundation engineering studies the fundamentals of soil mechanics in the applied fields.

The history of soil operation dates back to a long time ago, that is same as the history of the emergence of urbanization. Digging of canals, irrigation canals, building bridges and large dams and other constructions existed from tens of centuries ago, are all related to the soil applications. On the one hand, soil is the place where the structures are built in or on it. On the other hand, it is a substance used as building materials in the civil works. There are varieties of soils in the nature showing special behavior in the engineering applications. This variety in behavior and engineering properties is the result of many factors. For instance, the origin and formation of a soil have significant impact on the engineering properties. Therefore, the soil has different properties depending on the origin, alluvial, wind and debris types or toleration of the secondary changes.

The improvement of strength parameters in different soils is one of the important issues for researchers in geotechnical engineering. Adding additives to the soil is an effective method for improving some geotechnical properties of the soil. 
Moreover, the common additives, such as cement, calcite, calcium chloride, fly ash and bituminous have been investigated in the studies of other researchers [2-4].

There have been different methods for improving the soil since long time ago. According to the geotechnical engineering, the improvement methods of soils are divided into three general categories: Mechanical methods, chemical methods and soil reinforcement methods. The modification of soil behavior with the help of additives is one of the effective methods in improving most of the soil strength parameters considered by many geotechnical engineering researchers [5]. Soil stabilization with the chemical method has been used for most types of soils. The common additives such as cement, calcite, tar, ash, and polymer material have been used in different studies [6-7]. Besides these materials, the nanoparticles with unique properties have been the focus of few studies.

The nanoparticle is the particle with at least one dimension in nanoscale. Moreover, the particles with nanometer size show different behaviors with improved properties compared with the particles with the bigger size. The nanoparticles can affect the engineering properties and the physical and chemical behavior of the soil due to the properties, such as high specific surface, high electrical charge concentration and nanoporous, even with a low amount in the soil [8].

According to the nanotechnology is a branch of engineering that studies the particles smaller than 100 nanometers [9]. To modify some mechanical properties of the soil in civil projects, some additives can be used in the soil. To do this, the soil properties that need modification should be determined first. Then the type of additive should be selected based on the importance of the project, economical efficiency and the technical appropriateness. The calcite and nanocalcite are the examples of the additives with economic and technical justification in most cases. For instance, an urban project in Pennsylvania starts with a tradition design approach of 29.3 million dollars. An alternative design with calcite stabilization, compatible with experimental and mechanical-experimental designs of American Association of State of Highway Transportation Officials (ASHTO), costs only 21.6 million dollars saving more than $25 \%$ of the expenses. Besides, the stabilization with calcite decreases the maintenance expenses in long-term.

Accordingly, a sub-grade stabilization of 8-inch clay with calcite as a part of asphalt pavement can decrease the longterm cycle in 30 years from 24.49 to 22.47 per square yards [6]. Although there have been few studies evaluating the advantages of adding some types of nanoparticles to the soil, a big gap exists in conducting the experiments and scientific data in this field. The nanotechnology has been developed as an interdisciplinary space in the recent years. Furthermore, the nanoparticles have unique properties that was not used in the geotechnical issues very much, despite its stunning results in other sciences [7].

The current study aims at investigating the effect of adding the different percent of typical calcite powder and the same crushed powder in nanoscale on improving the properties of lean clay. To do this, a lean clay was prepared from a region in north-east of Iran, located in Golestan province and the road of Minoodasht to Azadshahr near the Aq Imam Path (figure 1). This type of soil has a clay loess origin and may show considerable subsidence. Moreover, about $37 \%$ of the soils in Golestan are lean clay and many population centers and villages were built in this type of soil. Therefore, improving the soil in the studied region is significant.

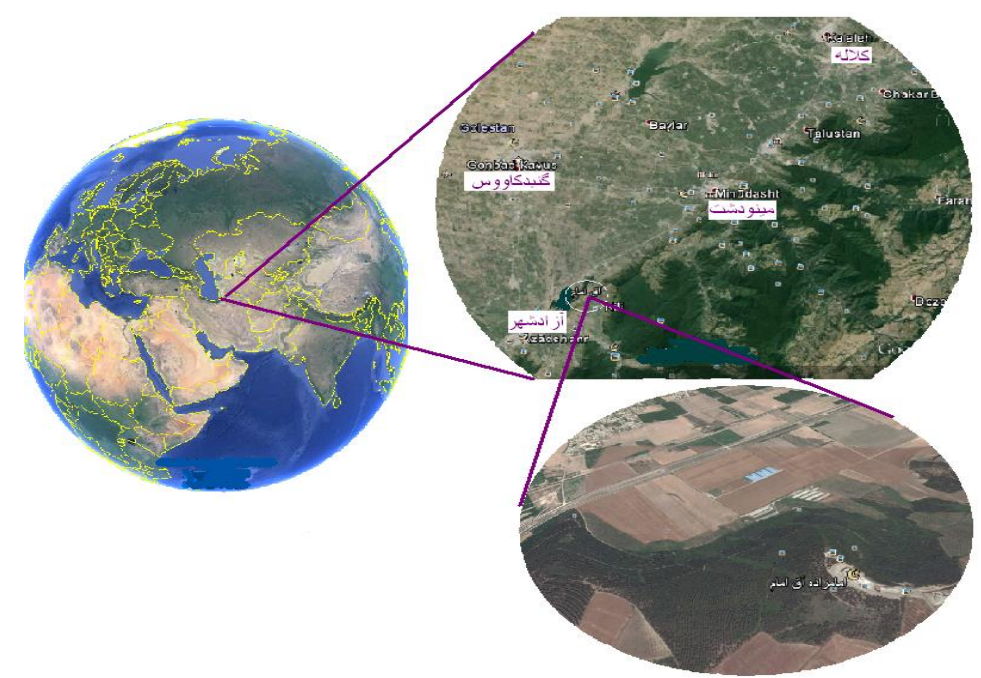

Fig. 1: The geographical location of the studied area. 


\section{Materials and Methods}

\subsection{The Studied Soil}

As stated earlier, the loess soil for this study was prepared from Aq Imam Path. The grain size distribution curve of this soil were indicated in Figure 2 and the properties of the studied soil were presented in Table 1. Furthermore, the results of the X-Ray tests on the nanocalcite powder were presented in Figure 3 and the results of the SEM tests were shown in Figure 4. According to the results, the soil was classified to CL type based on the unified classification system.

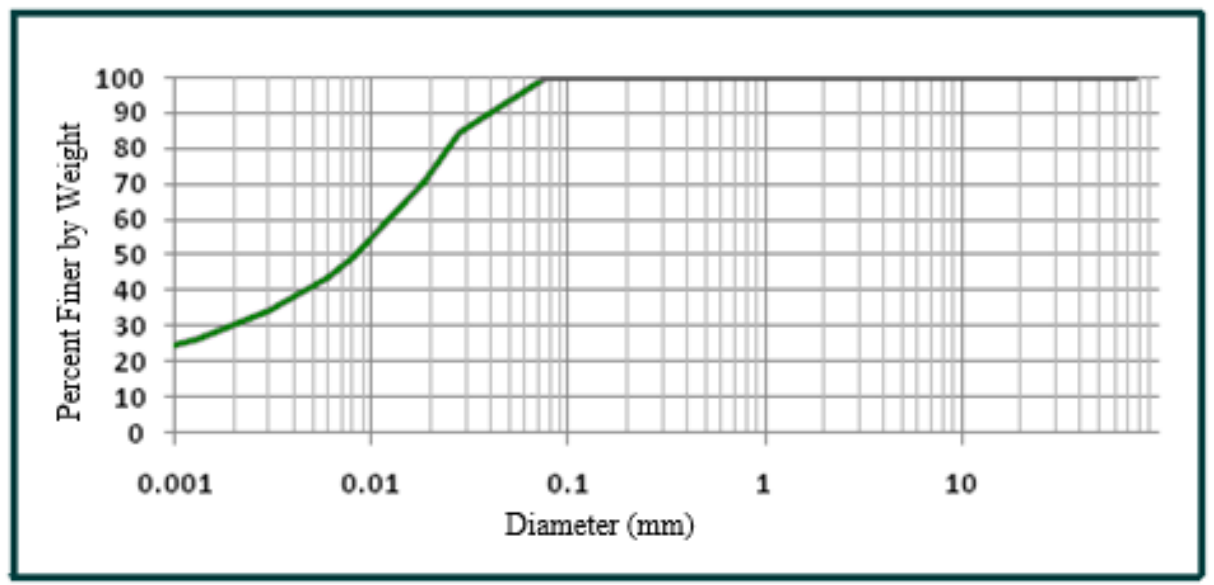

Fig. 2: The grain size distribution curve of the studied soil.

Table 1: The main geotechnical properties of the studied soil.

\begin{tabular}{|l|l|l|c|c|c|}
\hline $\begin{array}{c}\text { Soil } \\
\text { Type }\end{array}$ & Color & $\begin{array}{l}\text { Unified } \\
\text { Classification }\end{array}$ & $\begin{array}{c}\text { Density } \\
(\mathrm{Gs})\end{array}$ & $\begin{array}{c}\text { Liquid } \\
\text { Limit }(\%)\end{array}$ & $\begin{array}{c}\text { Plastic } \\
\text { Limit }(\%)\end{array}$ \\
\hline Clay & Yellow & CL & 2.68 & 31.5 & 13.3 \\
\hline
\end{tabular}

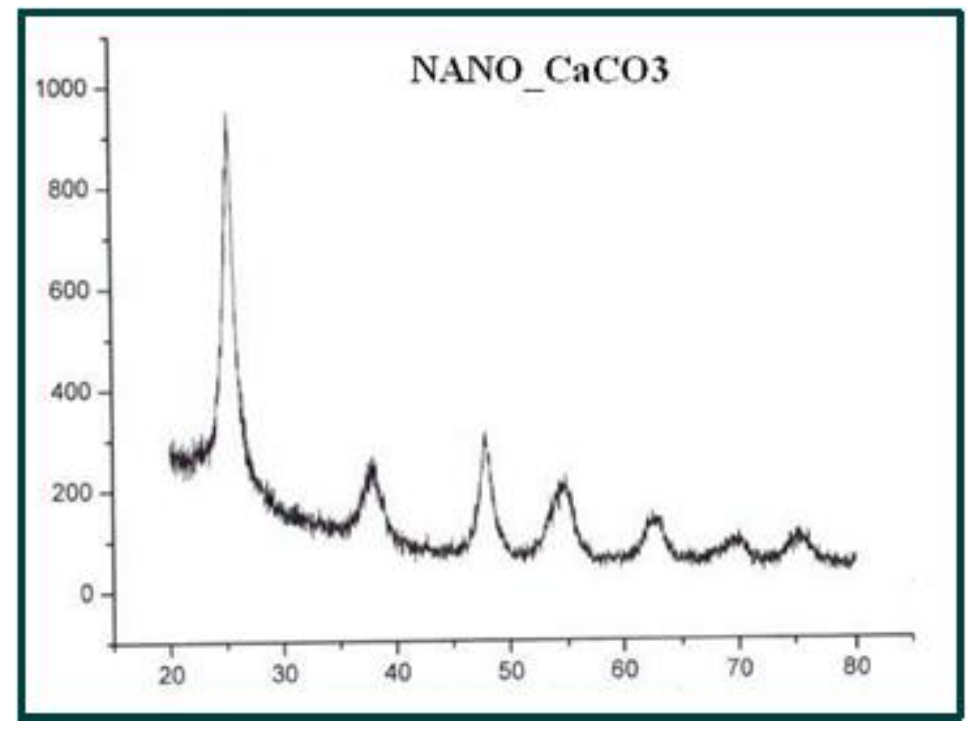

Fig. 3: The results of the X-Ray test on the nanocalcite samples. 


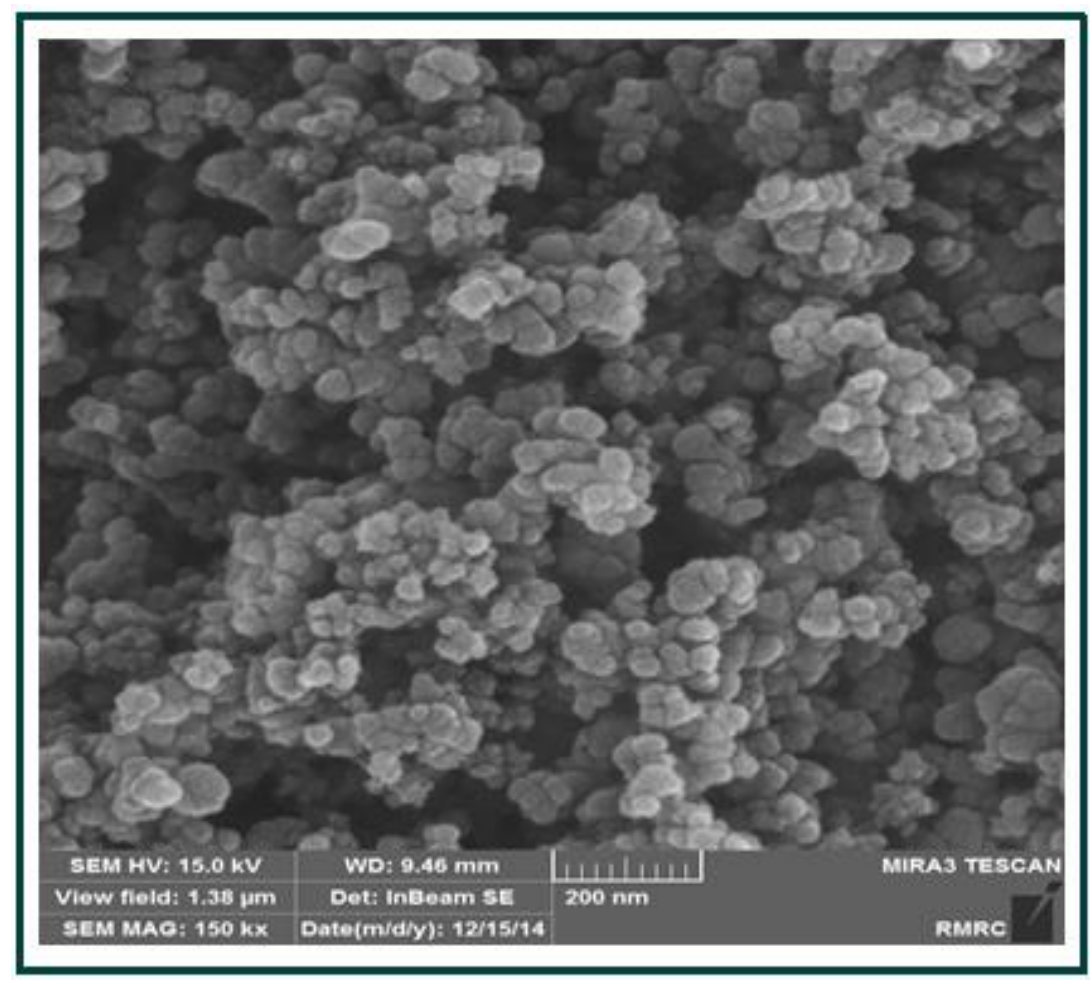

Fig. 4: The results of the SEM test on the nanocalcite samples.

\subsection{Calcite}

Pure calcite is white, but some impurities can change its color. If the impurities of limestone are magnesium carbonate, it is called Dolomitic limestone and baking it leads to magnesium calcite. Furthermore, if the impurity of the limestone is clay and silica materials, blue or semi-blue calcite will be produced depending on the degree of impurity. The advantages of adding calcite to the constructing mortars are a decrement in the permeability of mortars and plastering to the water, decrement in the shrinkage resulting from mortar drying and stability of volume after hardening of mortar. On the other side, the advantages of adding calcite are decrement in the drying time of the mixture in the humid areas, decrement in the expansion and contraction rate influenced by the moisture, acceleration of clay clods breaking, increment in the strength, and decrement in the permeability of the moisture and increment in the durability and reliability of the soil [9].

Calcite is one of the materials that is suitable for improving and stabilization of the different soil types. Since many soils contain silica and silica-alumina compounds, adding some quick calcite (Cao) or hydrated calcite $(\mathrm{Ca}(\mathrm{OH})) 2$ and water are effective for creating a stable mixture. Based on the experiment, different types of clays with quickcalcite or hydrated calcite produce a compound with the same properties as cementation compounds [9].

The pozzolanic reaction increases the strength of the water and calcite mixture. Moreover, the PH of the mixture increases more than 12 by adding enough calcite to the soil. The increment in the PH leads to the increase in aluminate and silicate solutions in the soil and the release of these compounds in the clayey soil makes their combination with the calcium possible. The combination of silicate and aluminate with calcite creates the silicate and aluminate calcium. These pozzolanic-crystal materials are like cement. Furthermore, the pozzolanic reactions are the function of time and they continue until the existence of silicate and aluminate in the soil creating new crystals. These reactions are provoked as follows:

$$
\begin{gathered}
\mathrm{CaO}+\mathrm{SiO}_{2}+\mathrm{n} \mathrm{H}_{2} \mathrm{O} \rightarrow \mathrm{CaSiO}_{3}+\mathrm{n} \mathrm{HOH} \text { (Calcium silicate) } \\
\mathrm{CaO}+\mathrm{Al}_{2} \mathrm{O}_{3}+\mathrm{n} \mathrm{H}_{2} \mathrm{O} \rightarrow \mathrm{CaAl}_{2} \mathrm{O}_{3}+\mathrm{n} \mathrm{HOH} \text { (Calcium aluminate) }
\end{gathered}
$$


In addition, the pozzolanic reactions are dependent on the clay percent in the soil. According to the studies, the amount of clay should not be lower than $20 \%$ in general. Apart from the time, these reactions are the function of the temperature and humidity. In the temperature lower than 55 centigrade degrees, the pozzolanic reactions are slow and the pace increase in higher temperatures. It should be noted that the increment in calcite to certain degrees increases the strength of the soil until there is silicate ion in the soil. Then, the increment of calcite decreases the strength. Therefore, the mix-design that is appropriate for the target soil should be prepared before conducting the project of soil stabilization with calcite.

During this reaction, the calcite is combined with the carbon dioxide in the air creating a weak cohesive material (upper plastic) and also results in the return of calcite to the inactive mode of limestone [7]:

$$
\mathrm{CaO}+\mathrm{CO} 2 \rightarrow \mathrm{CaCO} 3
$$

Since the carbonation can be occur during the combination of soil and calcite (while construction and execution), the combination time should be minimized as possible. Moreover, there is another form of carbonation reaction that occurs when the hydrated calcite is used. The result of this reaction is the carbonic acid which reacts with the calcium hydroxide and produces the calcium carbonate [7]:

$$
\begin{gathered}
\mathrm{H} 2 \mathrm{O}+\mathrm{CO} 2 \rightarrow \mathrm{H} 2 \mathrm{CO} 3 \\
\mathrm{H} 2 \mathrm{CO} 3+\mathrm{Ca}(\mathrm{OH}) 2 \rightarrow \mathrm{CaCO} 3+2 \mathrm{H} 2 \mathrm{O}
\end{gathered}
$$

Accordingly, if the amount of clay is not enough or there is an excessive amount of calcite in the soil, the improvement of soil with calcite is inefficient, due to the creation of $\mathrm{CaCO}$. Furthermore, the optimum percent of calcite and optimum moisture of the combination plan should be determined by experiment [7].

\section{Test Results}

In order to prepare the samples, typical calcite powder with 3, 4, 6 and $7 \mathrm{wt} \%$ and nanocalcite powder with $0.5,1,1.5$ and $2 \mathrm{wt} \%$ were added to the lean clay soil. The mixing should be continued until reaching a homogenous sample, which needs about 45 minutes of mixing using an electric mixer. For this purpose, the mixer was used with a slow speed so that the additive would not be separated (a hand mixer can be used too). Then, the distilled water was added to each sample and after a complete mixing of water with the soil mixture, calcite powder, and nanocalcite, the samples were kept in a closed container for 16 hours. The reason for this action was that the absorption of moisture in clay particles is a time-consuming process.

Next, enough water was added to the samples in that the number of blows is in the range of 15 to 30 . Based on the ASTM D-4318, part of this plastic was put in the brass cup of Casagrande with a spatula and the surface was smoothed with a spatula so that the surface of the soil was almost horizontal. Then the top of the cup was furrowed to the bottom with the furrowing tool so that the maximum depth of soil in the cup was 1 centimeter. During the furrowing, the surface of the furrow should be perfectly vertical to the cup surface. After creating the furrowing, the Casagrande hand was rotated with the pace of 2 blows per second and the number of hits needed for making the two soil halves close together in the bottom of the cup was counted based on the 12.7-milcalcitetre length. The experiment was repeated for 3 or 4 times and the moisture percent was related to 25 hits of the liquid limit. The changes in the moisture percent against the number of blows were obtained by drawing the semi-logarithmic curve.

The plastic limit was also determined by the mixing the clay soil, calcite and the nanocalcite with some distilled water until there was a soft and uniform sample. Then the samples were rolled by pressing with fingers and making it like an oval mass. This action was repeated until there were wicks with about 3.2-milimeter diameter and also the longitudinal and transverse cracks. The moisture percent of this stage is the plastic limit.

The results of the Atterberg limit and plastic index tests for the main soil and the modifications after adding the calcite and nanocalcite were presented in the Figures 5 and 6. 


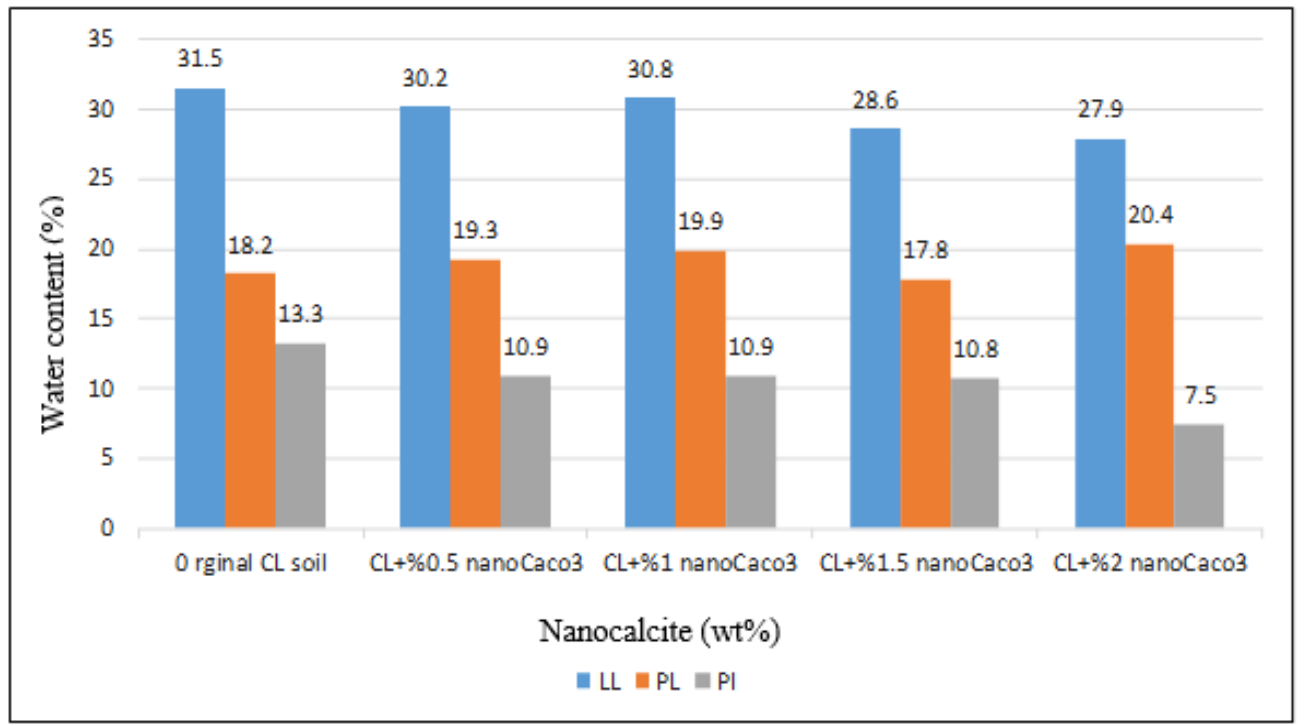

Fig. 5: The results of Atterberg limit tests for original lean clay and with the different percent of calcium nanocarbonate.

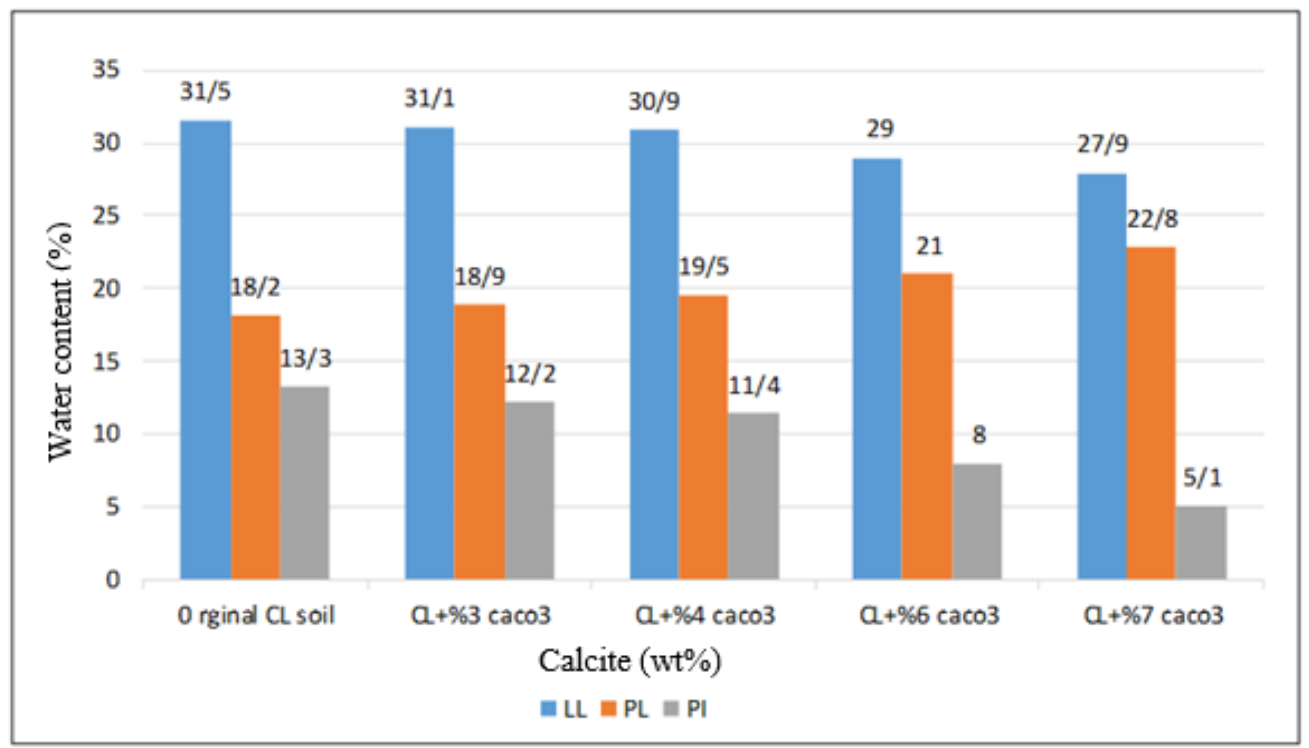

Fig. 6: The results of Atterberg limit tests for original lean clay and with different percent of calcite.

\section{Conclusion}

Generally, the soil containing enough amount of clay is appropriate for improvement with calcite powder. Moreover, the previous studies indicated that the result of using calcite is a decrement in PI and increment in the strength of soil. But the calcite is effective when the PH of soil was more than 10 and if the PH was lower than 10, the cement should be used for modification or stabilization. Besides, this cannot be true in all cases because there are some soils that have $\mathrm{PH}$ lower than 10, but they react well to the calcite.

The current study conducted the Atterberg limit tests on the samples containing 3, 4, 6 and $7 \mathrm{wt} \%$ of calcite and $0.5,1,1.5$ and $2 \mathrm{wt} \%$ of nanocalcite, to investigate the effect of adding calcite and nanocalcite powder on the plastic properties of the lean clay soil. The findings summarized as follow:

A. Adding calcite and nanocalcite powder to lead to the decrement of liquid limit and plastic index (the decrement of plastic index is desirable for improving the soils in geotechnical engineering), 
B. Adding the calcite and nanocalcite powder resulted in the increment of plastic limit in the soil. The nanocalcite was added for $0.5 \%$ in each increment, accordingly for adding $1 \%$ of nanocalcite, the plastic limit of the soil increased by about $2 \%$. However, for adding $1 \%$ of calcite to the soil, the plastic limit of the studied soil was increased by about $9 \%$,

C. According to the results, the effect of calcite on improving the soil in nanoscale is considerably higher than the typical calcite,

D. The investigation and observation of the improved samples by calcite and nanocalcite powder indicated that the use of these stabilizers led to the more brittle behaviour of the soil.

\section{References}

[1] Sh. Tahoni, "The fundamental of geotechnical engineering," Pars Aeein Publication, vol. 1, Tehran, 2011.

[2] D. Dermatas, and X. G. Meng, "Utilization of fly ash for stabilization /solidification of heavy metal contaminated soils," Engineering Geology, vol. 70, pp. 377-394, 2003.

[3] M. S. Gutierrez, "Potential Applications of Nano-mechanics in Geotechnical Engineering," Proc of the International Workshop on Micro-Geomechanics across Multiple Strain Scales, Cambridge, UK, pp. 29, 30, 2005.

[4] N. Naderi, S. A. Naeini, "The influence of polymer inclusion and plasticity index on the unconfined compression strength of clays," Proc. of the 2nd International Conf. on New Developments in Soil Mechanics and Geotechnical Engineering, Nicosia, 2009.

[5] A. Vafaei, S. Kootenai, A. Janalizadeh, "The effect of adding nanosilica and evaluating the mutual effect of cement and nanosilica on the strength behavior of the sands in Caspian coasts," National conference of civil engineering and urban development, 2014.

[6] H. Ganji, R. Fazli Ola, A. Norooznejad, "Investigating the change of soil shear stress before and after using the nanoclay," The ninth international conference in civil engineering, The technical university of Isfahan, 2012.

[7] A. Kavoosi, L. Hashemian, "The investigation of soil stabilization with calcite in Pas airport," The booklet of the first national conference on improving the earth, The technical university of Amirkabir, 2001.

[8] G. Zhang, "Soil nanoparticles and their influence on engineering properties of soils," GSP 173 Advances in Measurement and Modeling of Soil Behavior, New Peaks in Geotechnics, ASCE, 2007.

[9] A. Srivastava, and K. Singh, "Nanotechnology in Civil Engineering and Construction: A Review on State of the Art and Future Prospects," Indian Geotechnical Conference, Kochi, India, 2011. 